\title{
RENAL PATHOLOGY IN MALNOURISHED INFANTS
}

\author{
BY \\ G. A. STIRLING* \\ From The University College of the West Indies
}

(RECEIVED FOR PUBLICATION OCTOBER 13, 1961)

The purpose of this paper is to focus attention on the renal pathology complicating malnutrition in infancy.

\section{Methods and Materials}

The case histories, laboratory investigations and post-mortem records of all the malnourished infants dying in the Medical Research Council Tropical Metabolism Unit in Jamaica were studied. Out of a total of 37 cases six were rejected because the infants had died before biochemical investigations were made, or because the tissues were poorly preserved on account of the time which had elapsed between death and autopsy or, in one instance, because the kidneys were preserved intact and no histology was available. The remaining 31 infants were between the ages of 6 to 18 months with two exceptions who were 2 months and 4 months. All 31 infants were severely malnourished, and as far as one could judge from the dietetic history as well as the clinical and autopsy findings they were cases of primary malnutrition, i.e. the malnutrition was not secondary to some other disease.

Paraffin sections were prepared from the kidney tissue and stained with haematoxylin and eosin. Frozen sections from blocks of liver and kidney tissue were stained with Sudan IV.

Findings. Histology showed the following lesions (Table 1).

Six of the cases of cortical calcinosis as well as the case showing keratinization of the papillary epithelium (Fig. 1) are included as showing other renal pathology so that 22 of the 31 infants had renal lesions.

The serum electrolytes of the five infants with non-inflammatory lesions of the renal tubules are set out in Table 2. All were cases of protein malnutrition and therefore probably depleted of

\footnotetext{
- Present address: Department of Pathology, King's College Hospital, London S.E.5.
}

potassium, although this was not always manifest in the serum electrolytes (Smith and Waterlow, 1960).

TABLE 1

\begin{tabular}{llll|l}
\hline \multicolumn{3}{c|}{ Lesions } & & \\
\end{tabular}

TABLE 2

\begin{tabular}{|c|c|c|c|c|}
\hline \multirow{2}{*}{$\begin{array}{l}\text { Histological } \\
\text { Lesion }\end{array}$} & \multicolumn{4}{|c|}{$\begin{array}{l}\text { Serum Electrolytes on } \\
\text { Admission (mEq/1.) }\end{array}$} \\
\hline & $\mathrm{Na}$ & $\mathbf{K}$ & $\mathrm{Cl}$ & $\mathbf{M g}$ \\
\hline $\begin{array}{l}\text { Vacuolation of proximal tubules and } \\
\text { dilatation of distal tubules .. } \\
\text { Vacuolation of proximal tubules } \\
\text { Dilatation of proximal tubules } \\
\begin{array}{l}\text { Dilatation of proximal tubules } \\
\text { Acute tubular necrosis .. }\end{array}\end{array}$ & $\begin{array}{l}132 \\
121 \\
128 \\
113 \\
117\end{array}$ & $\begin{array}{l}3 \cdot 8 \\
3 \cdot 8 \\
2 \cdot 7 \\
4 \cdot 3 \\
1 \cdot 7\end{array}$ & $\begin{array}{r}70 \\
81 \\
112 \\
84 \\
\end{array}$ & $\begin{array}{l}0 \cdot 76 \\
- \\
-\end{array}$ \\
\hline
\end{tabular}

\section{Discussion}

The close association between malnutrition and infection is well known and is seen in the present study. An unusual feature was chronic renal infection in two infants (Fig. 2), both aged 8 months, and the presence of scarring which probably represented healed pyelonephritis in a third infant aged 10 months. Muehrcke (1959) reported chronic pyelonephritis as a frequent complication of prolonged potassium deficiency, while Smith and Waterlow (1960) have shown that protein starved children are depleted of potassium. This association of potassium deficiency and pyelonephritis may well be a factor in the high incidence of renal infection noted in the 


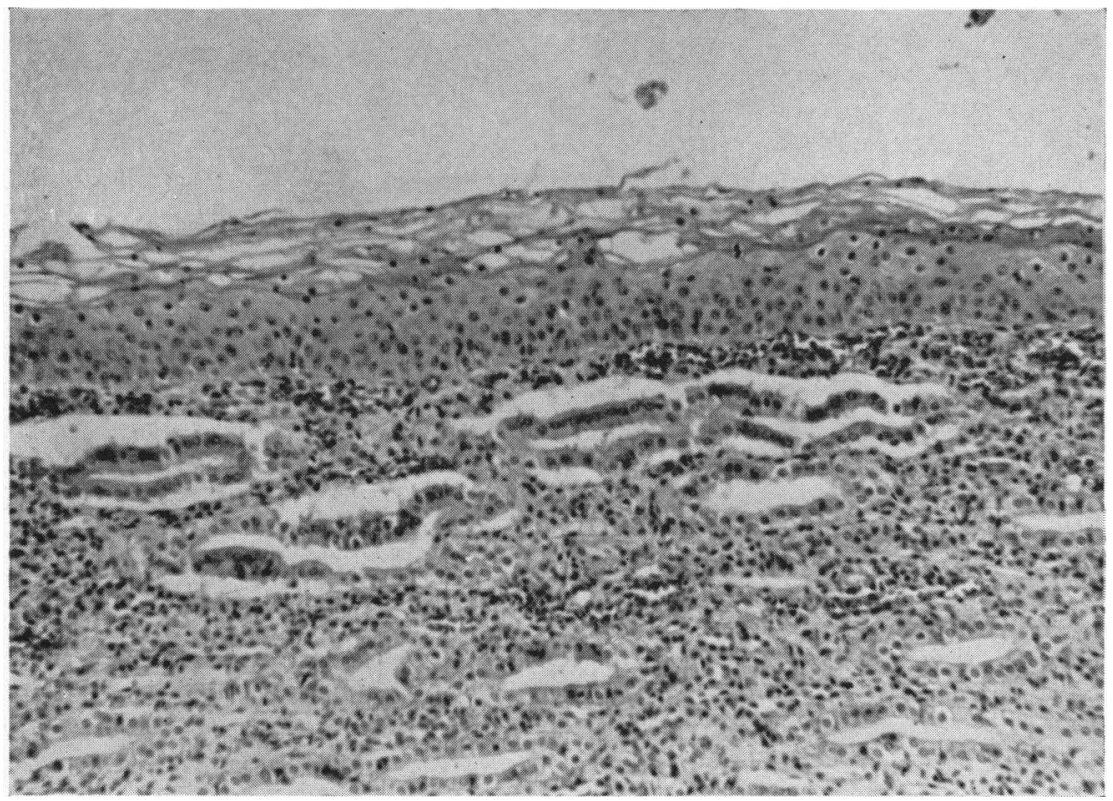

FIG. 1.-Keratinization of epithelium covering papilla.

(H. and E. $\times 40$.)

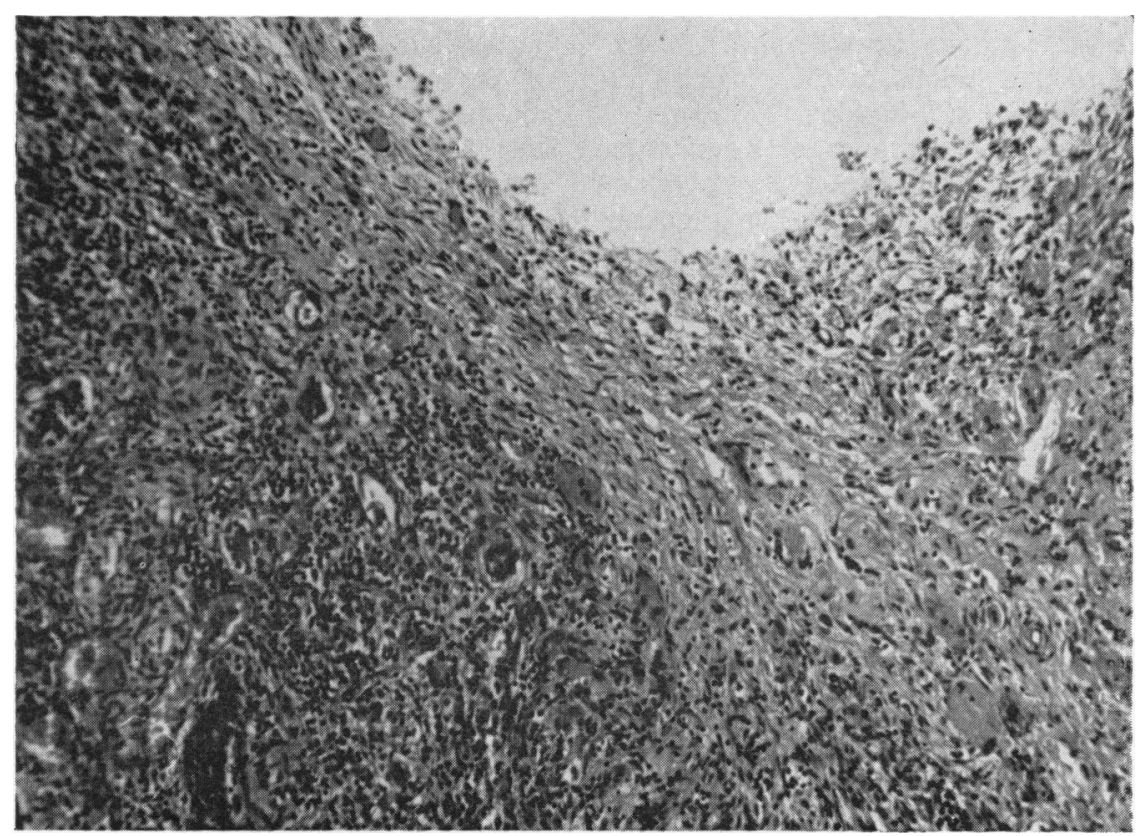

FIG. 2.-Chronic pyelonephritis in a child of 8 months. (H. and E. $\times$ 40.) 


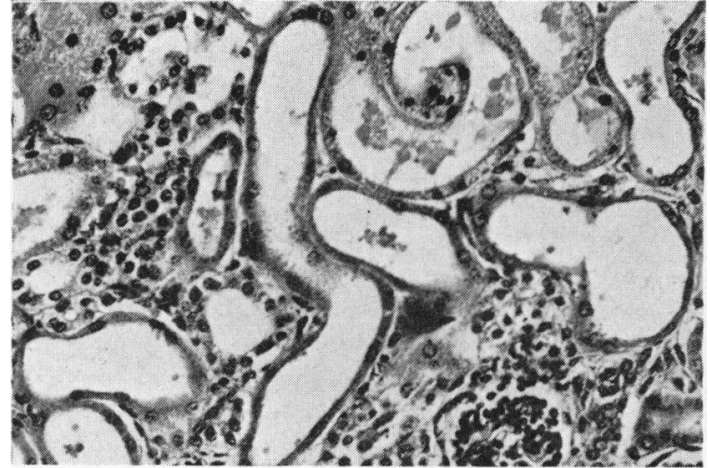

FIG. 3.-Acute tubular necrosis. (H. and E. $\times$ 157.)

present series. With regard to the three cases of acute pyelonephritis, it should be stated that it is not known whether any of these infants were catheterized after admission to hospital. In the cases of chronic pyelonephritis, on the other hand, inflammatory lesions were of some age and had obviously arisen before the admission of the babies to hospital.

In addition to depletion of potassium, protein malnutrition is known to be associated with profound electrolyte disturbances (Gómez, RamosGalván, Cravioto, Frenk, Janeway, Gamble and Metcoff, 1957). The majority of the infants in the present series were protein starved, and it is surprising therefore that lesions of the renal tubules were present in only five of the infants (Figs. 3 and 4). Perhaps more refined techniques of examination would reveal changes. The serum electrolytes of these five cases are given in Table 2, but it must be remembered that these infants were probably depleted of potassium although this was not manifest in their serum electrolytes. The multiplicity of the electrolyte disturbances in these cases, as well as the lack, with one exception, of serum magnesium readings, make it impossible to ascribe any one lesion to a particular electrolyte disturbance. Another difficulty is the lack of agreement as to the lesion in potassium deficiency. Relman and Schwartz (1956) have described foamy, swollen proximal tubular epithelium as well as dilatation of these same tubules with atrophy of the epithelium, whereas Muehrcke reported chronic pyelonephritis and interstitial fibrosis, but no vacuolation of tubular epithelium. In the experimental animal according to Oliver, MacDowell, Welt, Holliday, Hollander, Winters, Williams and Segar (1957), as well as KerpelFronius and his colleagues (Kerpel-Fronius, Romhányi, Gáti and Dobak, 1960), there was damage

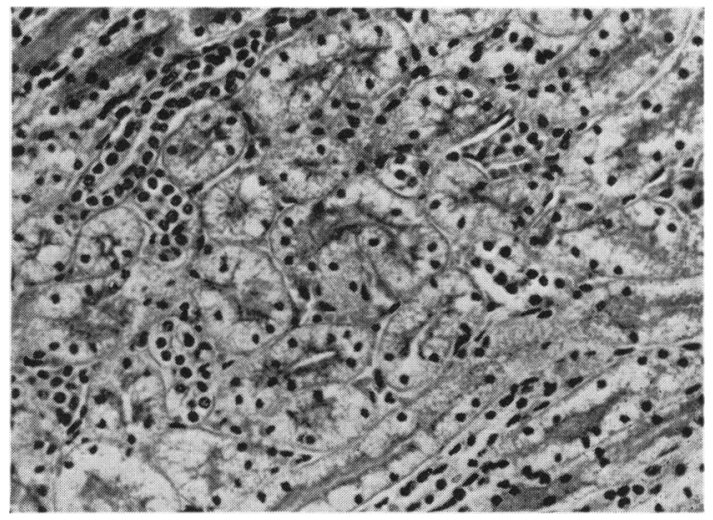

Fig. 4.-Vacuolation of proximal convoluted tubules. (H. and E. $\times 157$.

to the collecting tubules with secondary changes in the distal convoluted tubules. Moreover, dehydration may be concerned in these tubular lesions, particularly in acute tubular necrosis, because according to Black (1959) dehydration may be followed by shock and renal ischaemia giving rise to tubular damage.

The presence of subacute glomerulonephritis in one infant was probably another manifestation of infection, in this case streptococcal. This child's blood pressure was $170 / 120 \mathrm{~mm}$. $\mathrm{Hg}$, and the vessels showed the usual hypertensive changes, but in addition to these many arterioles were occluded or narrowed by sudanophilic material and one could not help but wonder how much this factor may have contributed to the malignant acceleration which was present.

Although minor degrees of nephrocalcinosis were ignored, there was a striking difference in the incidence in my material, $24 \%$, as compared with the $4 \%$ reported by Shanks and MacDonald (1959) in a group of Caucasian children. There was also a difference in the localization of the calcium. In the Caucasian series cortical calcification was rare whereas in the Jamaican infants it was restricted to the cortex, except in one case, in which a few calcific deposits were also present in the inner zone of the medulla. Shanks and MacDonald attributed their cases to hypercalcaemia, a condition known to be rare in our malnourished infants (E. E. Ward, 1961, personal communication). In the experimental animal, Hess and his colleagues (Hess, Macintyre, Alcock and Pearse, 1959) have described calcification of the inner cortex following magnesium deprivation. One infant with nephrocalcinosis had a low serum magnesium, but no estimation was made in the other infants. However, one must beware of 


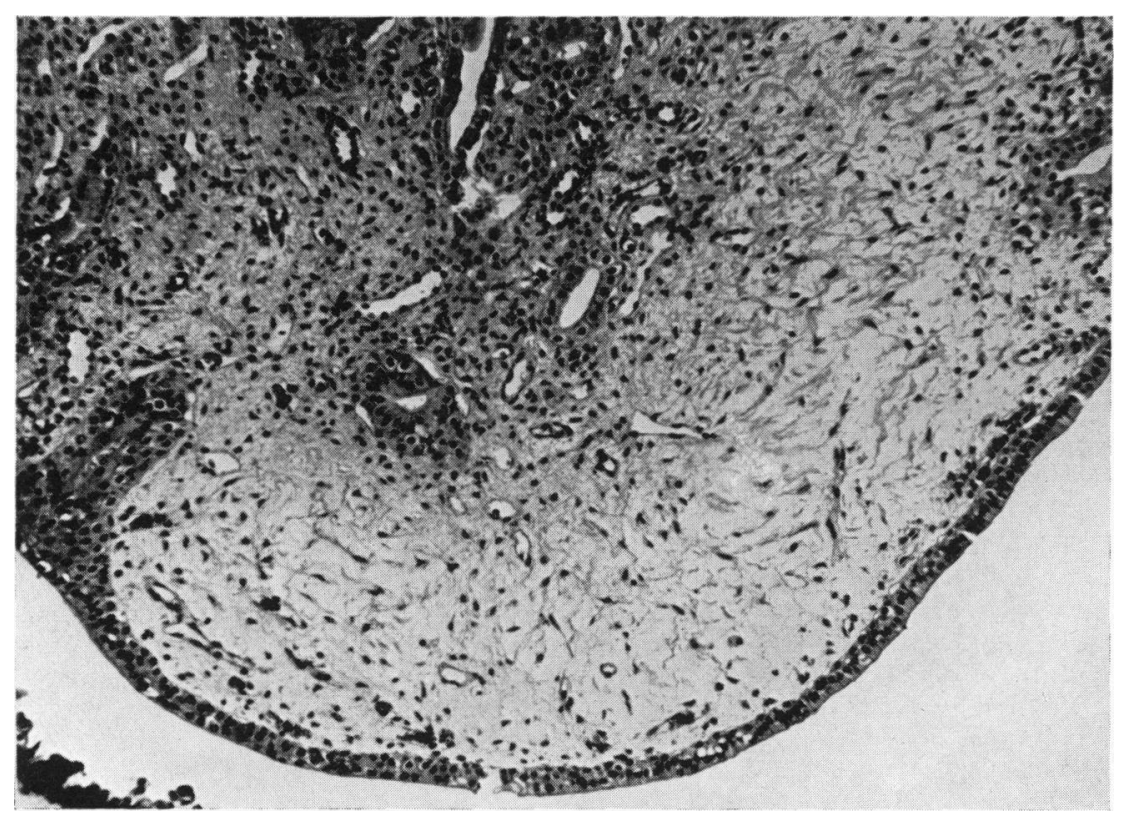

FIG. 5.-Fibrosis of renal papillae. (H. and E. $\times 40$.)

transposing observations on the experimental animal to human material, particularly in this instance, when all seven infants had electrolyte disturbances with a low alkali reserve in six instances and dehydration in at least five.

A curious lesion encountered in one infant was fibrosis of the tips of the renal papillae (Fig. 5). Biochemical deficiencies may be concerned. However, the papillae have relatively poor blood supply as compared with the rest of the kidney, since most of the blood reaches this area after it has passed through the glomeruli, and the role of ischaemia cannot be ignored.

Another unusual finding was a significant degree of renal fat embolism (Fig. 6) and, by inference, systemic fat embolism in two infants. In both a sudden deterioration of the condition of the infants was noted, but it would be unwise to attribute this to fat embolism since this sort of termination is not unusual in the malnourished without fat embolism. The liver in both cases showed chronic fatty change with rupture of parenchymal cells distended with fat. The presence of erythrocytes in some of these suggested a communication with blood vessels, and it is reasonable to assume that the emboli originated from these.

Malnutrition is common among infants of the poorer classes in Jamaica. The majority appear to recover completely, but the high incidence of renal pathology in the fatal cases suggests that many of those that recover may be left with residual renal damage.

\section{Summary}

Out of a total of 31 malnourished infants, 22 had renal lesions.

There was a high incidence of infection, both acute and chronic. The more unusual lesions included fat embolism and fibrosis of the renal papillae.

It was not possible to ascribe the lesions of the

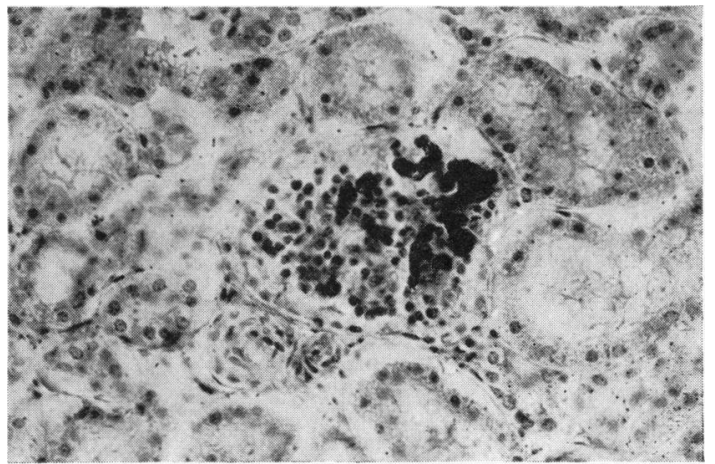

Fig. 6.-Fat embolism. (Sudan stain $\times 157$.) 
renal tubules to any particular biochemical deficiency.

It is suggested that many infants who apparently recover from malnutrition may have residual renal damage.

I am grateful to Professor John Waterlow for access to case histories and permission to publish this paper.

\section{REFERENCES}

Black, J. (1959). Renal tubular damage in infantile gastro-enteritis. Arch. Dis. Childh., $34,158$.

Gómez, F., Ramos-Galván, R., Cravioto, J., Frenk, S., Janeway, C. A., Gamble, J. L. and Metcoff, J. (1957). Intracellular composition and homeostatic mechanisms in severe chronic infantile malnutrition. Pediatrics, 20, 101.
Hess, R., Macintyre, I., Alcock, N. and Pearse, A. G. E. (1959). Histochemical changes in rat kidney in magnesium deprivation. Brit. J. exp. Path., 40, 80.

Kerpel-Fronius, E., Romhányi, G., Gáti, B and Dobak, E. (1960). Influences of depletion of potassium, of sodium, or of water on function and structure of the kidney. Pediatrics, 26, 939.

Muehrcke, R. C. (1959). In Biology of Pyelonephritis, ed. E. L. Quinn and E. H. Kass. Henry Ford International Symposium, No. 9. Little Brown, Boston, Mass.

Oliver, J., MacDowell, M., Welt, L. G., Holliday, M. A., Hollander, W., Jr., Winters, R. W., Williams, T. F. and Segar, W. E. (1957) The renal lesions of electrolyte imbalance. I The structural alterations in potassium-depleted rats. J. exp. Med., 106, 563.

Relman, A. S. and Schwartz, W. B. (1956). The nephropathy of potassium depletion; clinical and pathological entity. New Engl. J. Med., 255, 195.

Shanks, R. A. and MacDonald, A. M. (1959). Nephrocalcinosis infantum. Arch. Dis, Childh. 34, 115.

Smith, R. and Waterlow, J. C. (1960). Total exchangeable potassium in infantile malnutrition. Lancet, $1,147$. 